\title{
RELATIVE RISK FOR TB IN THE UNPROTECTED SMALL INDUSTRIAL ENVIRONMENT: A CASE STUDY
}

\author{
Athambawa Mohamed Razmy \\ Faculty of Applied Sciences, South Eastern University of Sri Lanka.
}

\begin{abstract}
Tuberculosis is still continuing to be a major public health problem in Sri Lanka. About 8000 new cases of $T B$ are notified every year. The incidences of Tuberculosis differ much within the country based on the environmental pollution and other factors such as occupation, nutrition and education levels and therefore the risk for tuberculosis also differs much within the divisional secretariat divisions. For this study the Sammanthurai divisional secretariat division which is having the small industries such as metal quarries and traditional brick manufacturing was selected to study the relative risk for tuberculosis. The relative risk for tuberculosis was estimated using linear logistic models. This studied area had 2.89 folder higher relative risk for tuberculosis compare to the national incidence. Within this studied division an area called J block was identified as more susceptible area for tuberculosis. Presence of higher number of metal quarries, traditional brick manufacturing industries, low level of education and low income might be the causes for this increased relative risks. An urgent measure to control dusts from these industries and providing safe work environment for the people working in these industries are vital.
\end{abstract}

Keywords: Average annual risk, Incidence of tuberculosis, Relative risk, Tuberculosis

\section{Introduction}

Tuberculosis (TB) is a common and in many cases lethal, infectious disease caused by various strains of mycobacteria, usually Mycobacterium tuberculosis (Kumar et al., 2007). This disease first attacks the lungs than other parts of the body. This is spread through air while active TB patients cough and sneeze (Konstantinos, 2010). Most infections are asymptomatic and latent, but about one in ten latent infections eventually progresses to active disease which, if left untreated, kills more than $50 \%$ of those so infected. TB is second only to HIV/AIDS as the greatest killer worldwide due to a single infectious agent. The symptoms of $\mathrm{TB}$ are persistent cough, constant fatigue, weight loss, loss of appetite, fever, coughing up blood and night sweats (Steven et al.,1998). Management of early symptoms and adherence to medical treatment are main challenges in controlling TB (Sagbakken et al., 2008). In 2011, 8.7 million people fell ill with TB (WHO, 2010). TB kills nearly 2 million people annually, yet rapid diagnosis still relies on a 100-year-old method of sputum staining for acid-fast bacilli (Syhre and Chambers, 2008). Over 95\% of TB deaths occurred in low- and middle-income countries (Center for disease control and prevention, 1990). Reporting of cases and deaths in developing countries is incomplete and the burden of TB can be estimated indirectly using the average annual risk of TB infection (ARI). ARI represents the probability that any person will be infected or reinfected with Mycobacterium tuberculosis in 1 year (Garcia et al., 1992). ARIs are calculated from tuberculin skin test surveys of representative samples of non-BCG-vaccinated persons (Cauthen et al., 1998). The ARI was the highest in Africa (1.5\%-2.5\%) and Asia (1.0\%-2.0\%) and lowest in Europe (0.012 \%) (Styblo, 1989). TB is still continuing to be a major public health problem in Sri Lanka and the incidence of tuberculosis is 0.089\% (Trading Economic, 2011). The majority of these patients are significantly malnourished (Metcalfe, 2005). About 8000 new 
cases of tuberculosis are notified every year, of which around $60 \%$ are smear-positive pulmonary TB cases. The incidence of TB differs much within the divisional secretariat (DS) divisions depending on various demographic factors and environmental pollution levels. Sammanthurai DS division in Sri Lanka is one of the vulnerable division for TB because of having small industries such as metal quarries and traditional brick manufacturing. In this DS division, the relative risks of TB was studied for two distinct areas J block and Sammanthurai town.

\section{Methodology}

The J block of the Sammanthurai DS division which is believed to be more vulnerable for TB has the total population of 27,375 and the rest of the area (Sammathurai town) has the population of 41,063. 176 TB patients were identified during the study period of three years in this DS division. The relative risks were estimated using linear logistic models after logit transformations of the proportions and for interpretation the estimations were back-transformed to the original scale.

\section{Results and Discussion}

The incidence of TB in this DS division was $0.26 \%$ which significantly greater than the national incidence of $0.089 \%(\mathrm{P}<0.000)$. $0.34 \%$ and $0.20 \%$ of incidences were observed in the J block and town respectively. The Sammanthurai DS division had 2.89 (95\% CI, $2.24,3.74)$ folder higher relative risk for $\mathrm{TB}$ compare to the national incidence. The living pattern and the environmental pollution might be the reason for higher incidence. The J Block had 1.65 (95\% CI, 1.22, 2.21) folder higher relative risk for TB compare to town area. Presence of several metal quarries and brick manufacturing industries might be the reason for this increased relative risks. Figure 1 shows the percentage of TB patients under different age groups for $\mathrm{J}$ block and town. It was observed that $48 \%$ of the TB patients were in the age group of $45-64$ and the chi-square analysis showed the incidence of TB was higher in early ages in the J block ( $\mathrm{P}$ $=0.032$ ).

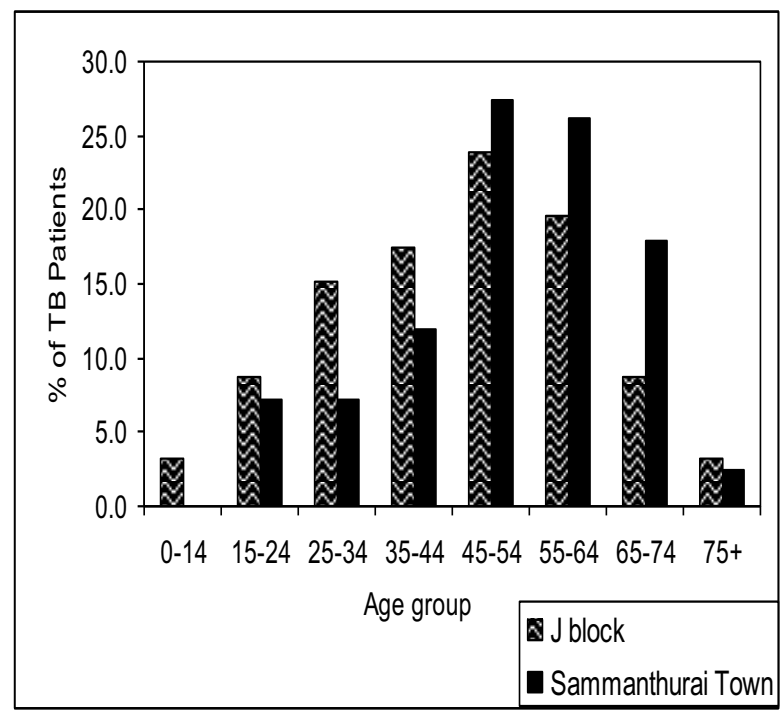

Figure 1: Percentage of TB patients under different age groups

No association was found between TB and gender in both areas studied $(\mathrm{P}=0.011)$. Incidences of $\mathrm{TB}$ in Muslim and Tamil communities were $0.30 \%$ and $0.08 \%$ respectively and the chi-square analysis showed this difference is significant $(\mathrm{P}<0.001)$. It is significant to note that no TB patient had studied more than G.C.E A/L and the educational level of the J block patients were less compare to the town patients. All the observed TB patents' monthly incomes were less than Rs. 20,000.00. and the monthly income of the TB patients in the $\mathrm{J}$ block was significantly less compare to the town patients. $51 \%$ of the TB patients in the $\mathrm{J}$ block and $60 \%$ of the TB patients in the town had at least one of the bad habits such as smoking, alcoholism and beetle chewing. Occupation played a significant role in TB that $37.5 \%$ of the patients' occupation was stone making and another $25 \%$ were famers. A serious concern is essential in this DS division for achieving TB free Sri Lanka. ARI modeling will forecast the future risk for TB in this DS division better that relative risk models but it needs more parameters such as detection rate, cure rate and relapse rates. An urgent measure to control dusts 
from these industries and providing safe work environment for the people working in these industries in this DS division are vital.

\section{References}

Cauthen GM, Pio A, ten Dam HG. Annual risk of tuberculous infection. Geneva: World Health Organization, 1988; document no. $\mathrm{WHO} / \mathrm{TB} / 88.154$.

Center for disease control and prevention (1990), Tuberculosis in Developing Countries Morbidity and Mortality Weekly Report Vol. 39, No. 33, pp. 561, 567-569.

Garcia A, Mccario J, Richarson S (1992), Modeling the Annual Risk of Tuberculosis Infection. International Journal of Epidemiology Vol. 26, No. 1, pp. 190 -203.

Konstantinos A (2010), "Testing for tuberculosis". Australian Prescriber Vol. 33, No. 1, pp. 12-18.

Kumar V, Abbas AK, Fausto N, Mitchell RN (2007). Robbins Basic Pathology (8th ed.). Saunders Elsevier: pp. 516-522.

Metcalfe N (2005), A study of tuberculosis, malnutrition and gender in Sri Lanka. Trans $R$ Soc Trop Med Hyg. Vol. 99, No. 2, pp. 115-119.

Sagbakken M, Frich JC, Bjune GA (2008), Perception and Management of Tuberculosis Symptoms in Addis Ababa, Ethiopia. Quality Health Research Vol. 18, No. 10, pp. 1356-1366.

Steven ASCH, Barbara L, Ronald A, Lllian G (1998), "Why Do Symptomatic Patients Delay Obtaining Care for Tuberculosis?" American Journal of Respiratory and Critical Care Medicine Vol. 157, No. 4, pp. 1244-1248.

Styblo K. Overview and epidemiologic assessment of the current global tuberculosis situation with an emphasis on control in developing countries. Rev Infect Dis 1989; II(2):S339S346.
Syhre, M, Chambers, ST (2008), The scent of Mycobacterium tuberculosis. Tuberculosis. $88(4)$ : 317-323.

Trading Economic (2011), Incidence of tuberculosis in Sri Lanka. http://www.tradingeconomics. com/srilanka/incidence-of-tuberculosis-per-100-000people-wb-data.html. Accessed June, 12013.

World Health Organization (2010), Tuberculosis fact sheet. http://www.who.int/mediacentre/ factsheets/ fs104/en/index.html. Accessed March, 212010. 